\title{
PENGARUH SUHU TERHADAP OKSIDASI FENOL MENGGUNAKAN MANGAN OKSIDA HASIL SINTESIS DARI MALTOSA DAN KMNO 4 DENGAN METODE SOL-GEL
}

\author{
Hafizhah$^{1}$, Amir Awaluddin', ${ }^{2}$ Muhdarina ${ }^{3}$ \\ 1. Mahasiswa Program Studi S2 Kimia \\ 2. Bidang Kimia Anorganik Jurusan Kimia FMIPA Universitas Riau \\ 3. Bidang Kimia Fisika Jurusan Kimia FMIPA Universitas Riau \\ Kampus Binawidya Pekanbaru, 28293, Indonesia \\ h.fizhah@ymail.com \\ amirawaluddin01@gmail.com
}

\begin{abstract}
ABSTRAK
Mangan oksida hasil sintesis menggunakan metode sol-gel dengan perbandingan prekursor $\mathrm{KMnO}_{4}$ dan maltosa (4: 1). Karakterisasi struktur mangan oksida menggunakan difraksi sinar-X untuk menentukan struktur, tingkat kristalinitas dan tingkat kemurnian, Scanning Electron Microscopy (SEM) untuk menentukan morfologi dan ukuran partikel, dan luas permukaan dengan metode metilen biru. Hasil menunjukkan bahwa mangan oksida hasil sintesis merupakan campuran mangan oksida berongga type cryptomelane dan hausmanite, adapun karakterisasi dengan SEM menunjukkan partikel mangan oksida berbentuk seperti gumpalan-gumpalan awan dengan ukuran partikel \pm 1 $\mu \mathrm{m}$ dan luas permukaan $10,716 \mathrm{~m}^{2} / \mathrm{g}$. Penelitian ini bertujuan untuk mempelajari kemampuan mangan oksida sebagai katalis pada proses oksidasi fenol. Oksidasi fenol dilakukan pada variasi suhu reaksi $\left(30^{\circ} \mathrm{C}, 40^{\circ} \mathrm{C}, 50^{\circ} \mathrm{C}\right.$ dan $\left.60^{\circ} \mathrm{C}\right)$ dan waktu reaksi $(30,60,90,120,150$ dan 180 menit). Hasil optimum menunjukkan bahwa katalis mangan oksida sebanyak $0,1 \mathrm{~g}$ dapat mengoksidasi fenol pada konsentrasi $100 \mathrm{ppm}$ sebesar $92,7 \%$ pada suhu $60^{\circ} \mathrm{C}$ di menit ke-150. Kajian kinetik menunjukkan bahwa oksidasi fenol mengikuti orde satu dengan energi aktivasi sebesar 2,19 $\mathrm{kJ} / \mathrm{mol}$
\end{abstract}

Kata kunci: Fenol, Mangan Oksida, Oksidasi, Kinetika Reaksi, Sol-gel

\section{PENDAHULUAN}

Mangan oksida telah diteliti secara intensif selama beberapa dekade karena nilai ekonominya dan potensinya dalam berbagai aplikasi. Aplikasi mangan oksida yaitu sebagai bahan katoda pada baterai lithium karena kemampuannya sebagai penukar kation (Liu dan Ooi, 2003). Disamping itu mangan oksida digunakan sebagai adsorben (Lu dkk., 2007), dan sebagai katalis untuk mengoksidasi CO (Matsuda dkk., 2007). Kemampuan mangan oksida sebagai katalis dipengaruhi oleh sifat fisika dan kimia yang dimilikinya. Metode dan kondisi preparasi yang berbeda juga memberikan pengaruh terhadap bentuk dan struktur permukaan serta kemampuannya sebagai katalis.

Fenol merupakan polutan organik berbahaya yang terdapat dalam limbah cair industri penyulingan minyak bumi, gas, farmasi, tekstil dan rumah tangga (Lestari, 2013). Polutan fenol jika dibuang ke lingkungan perairan akan membahayakan kehidupan makhluk hidup di sekitarnya. Pada konsentrasi tertentu, polutan fenol dapat memberikan efek yang buruk terhadap manusia, antara lain berupa kerusakan hati, penurunan tekanan darah, pelemahan detak jantung, hingga kematian (Slamet dkk., 2005).

Telah banyak metoda yang digunakan untuk penanganan limbah yang mengandung polutan fenol baik secara kimiawi maupun biologi. Zultinar dan Yenti (2011) telah melakukan penelitian adsorpsi fenol menggunakan kitin sebagai adsorben. Konsentrasi awal fenol 100 ppm berhasil di serap sebanyak 4,479 ppm pada suhu $30^{\circ} \mathrm{C}$ selama 60 menit. Adapun degradasi fenol secara biologi telah dilakukan oleh Dewilda (2012) menggunakan bakteri Acinetobacter $s p$ dan Bacillus sp. Penurunan konsentrasi senyawa fenol optimum terjadi pada jam ke-36 sebesar $71 \%$. Proses degradasi ini tidak menguntungkan untuk penanganan fenol dengan konsentrasi tinggi karena berlangsung lambat. 
Metode yang sedang dikembangkan dan efektif untuk mengatasi polutan organik yaitu oksidasi kimia yang dikenal dengan istilah Advanced Oxidation Processes (AOP). Proses oksidasi dilakukan dengan mereaksikan senyawa organik dengan oksidan pada kondisi temperatur diatas $200{ }^{\circ} \mathrm{C}$ dan tekanan 1 - $20 \mathrm{MPa}$ (Munter, 2001). Metode ini menghasilkan sejumlah radikal aktif yang berperan dalam degradasi senyawa pencemar (Inchaurrondo dkk, 2012). Penambahan katalis pada metode ini berperan dalam meningkatkan laju oksidasi (Wang dkk., 2012).

Katalis yang telah digunakan untuk oksidasi fenol yaitu Cu/ZSM5 (Valkaj dkk., 2011), Ru/AC (Muhammad., dkk 2011), $\mathrm{NiAlCO}_{3}$ (Zhou dkk., 2011), $\mathrm{Fe}_{2} \mathrm{O}_{3}$ dan $\mathrm{MnO}_{2}$ (Chaliha dan Bhattacharyya, 2006). Beberapa oksida mangan lain seperti $\mathrm{MnO}, \gamma-\mathrm{Mn}_{3} \mathrm{O}_{4}, \gamma-\mathrm{Mn}_{2} \mathrm{O}_{3}, \alpha-, \beta-$, dan $\gamma-\mathrm{MnO}_{2}$ (Saputra dkk., 2013) juga telah digunakan untuk mengoksidasi fenol. Oksidasi fenol dengan katalis oksida logam tersebut berlangsung pada suhu $18-80{ }^{\circ} \mathrm{C}$ dalam waktu kurang dari 180 menit.

Penelitian ini memfokuskan pada penggunaan mangan oksida sebagai katalis untuk oksidasi fenol dalam air pada skala laboratorium. Mangan oksida disintesis dengan metode sol-gel menggunakan prekursor $\mathrm{KMnO}_{4}$ dan maltosa berdasarkan penelitian Ginting (2011) yang menunjukkan bahwa pada perbandingan mol $\mathrm{KMnO}_{4}$ : maltosa (4: 1$)$ menghasilkan cryptomelane murni. Penggunaan mangan oksida yang disintesis dengan metode sol-gel untuk oksidasi fenol belum pernah dilaporkan oleh peneliti-peneliti sebelumnya, sehingga diharapkan dengan sifat dan struktur permukaan mangan oksida ini dapat digunakan untuk oksidasi fenol dalam air.

\section{METODOLOGI PENELITIAN}

Jenis penelitian observasional analitik, dengan desain cross sectional. Penelitian ini dilakukan di RSUD Panembahan Senopati pada 2 Maret - 31 Mei 2014. Populasi dalam penelitian ini adalah semua ibu bersalin yang pernah atau sedang hipertensi selama masa hamil sampai bersalin dari bulan Januari-Desember 2013 sebanyak 191 orang. Jumlah sampel 100 subjek, diambil dengan simple random sampling. Pengumpulan data lapangan diambil dari data sekunder yaitu register ibu bersalin dan rekam medis dari JanuariDesember 2013, meliputi data usia, paritas, berat badan kunjungan pertama, tinggi badan, diagnosa medis. Analisis data menggunakan chi-square dan rasio prevalensi, dengan tingkat kepercayaan $95 \%$.

\section{Alat dan Bahan}

Peralatan yang digunakan untuk karakterisasi struktur adalah X-ray Difraktometer mAXIma X Shimadzu XRD-7000. Untuk analisis morfologi adalah Scanning Electron Microscopy (SEM) EVO-50 (ZEIZZ). Neraca analitik, Spektronik $20 \mathrm{D}$, sentrifuge, furnace, oven, dan $\mathrm{pH}$ meter.

Bahan-bahan yang digunakan dalam penelitian ini adalah maltosa $\left(\mathrm{C}_{12} \mathrm{H}_{22} \mathrm{O}_{11}\right)$, kalium permanganat $\left(\mathrm{KMnO}_{4}\right)$, hidrogen klorida $(\mathrm{HCl})$, fenol $\left(\mathrm{C}_{6} \mathrm{H}_{5} \mathrm{OH}\right)$, hidrogen peroksida $\left(\mathrm{H}_{2} \mathrm{O}_{2}\right)$, 4aminoantipirin $\left(\mathrm{C}_{11} \mathrm{H}_{13} \mathrm{~N}_{3} \mathrm{O}\right)$, kalium ferisianida $\left(\mathrm{K}_{3} \mathrm{Fe}\left(\mathrm{CN}_{6}\right)\right)$, ammonium hidroksida $0,5 \mathrm{~N}$ $\left(\mathrm{NH}_{4} \mathrm{OH}\right)$, kalium dihidrogen fosfat $\left(\mathrm{KH}_{2} \mathrm{PO}_{4}\right)$, dikalium hidrogen fosfat $\left(\mathrm{K}_{2} \mathrm{HPO}_{4}\right)$, kertas saring Whatman no.42, dan akuades.

\section{Sintesis Mangan Oksida}

Sebanyak 4,55425 gram $(0,25 \mathrm{~mol})$ maltosa ditambahkan ke larutan $\mathrm{KMnO}_{4}$ yang dibuat dengan melarutkan 15,804 gram $\left(0,1 \mathrm{~mol} \mathrm{KMnO}_{4}\right.$ dalam $1 \mathrm{~L}$ akuades $(0,1 \mathrm{~mol})$ sambil diaduk. Setelah \pm 4 menit, terbentuk sol yang kemudian akan berubah menjadi gel. Setelah didiamkan pada suhu kamar selama satu jam, gel yang terbentuk disaring dan dicuci sebanyak 4 kali dengan akuades $250 \mathrm{~mL}$, kemudian dikeringkan pada temperatur $110^{\circ} \mathrm{C}$ selama 24 jam. Hasil xerogel, dikalsinasi pada temperatur $450^{\circ} \mathrm{C}$ selama dua jam. Produk yang terbentuk dihaluskan, dicuci masing-masing 3 kali dengan $10 \mathrm{~mL} \mathrm{HCl}$ 0,1 M dan akuades. Produk dikeringkan pada temperatur $110^{\circ} \mathrm{C}$ untuk dikarakterisasi.

Karakterisasi struktur dilakukan menggunakan difraksi sinar-X. Analisis morfologi dilakukan dengan menggunakan Scanning Electron Microscopy (SEM). Luas permukaan mangan oksida ditentukan menggunakan metode adsorpsinya terhadap metilen biru yang diukur dengan spektrofotometer UV-Vis. 


\section{Proses Oksidasi Fenol}

Larutan fenol (100 ppm) sebanyak $200 \mathrm{~mL}$ dimasukkan ke dalam erlenmeyer dan diaduk dengan kecepatan $600 \mathrm{rpm}$. Katalis mangan oksida sebanyak 0,1 gram ditambahkan kedalam larutan. Campuran fenol dan katalis dipanaskan pada temperatur $30^{\circ} \mathrm{C}$. Setelah mencapai suhu yang diinginkan, hidrogen peroksida $30 \%$ ditambahkan untuk memulai proses reaksi. Campuran diambil pada menit ke 30, 60, 90, 120, 150, dan 180. Campuran kemudian didinginkan dan disaring. Analisis konsentrasi fenol yang tersisa dilakukan dengan spektrofotometer UVVis. Prosedur yang sama dilakukan untuk suhu 40, 50, dan $60^{\circ} \mathrm{C}$.

\section{HASIL DAN PEMBAHASAN Sintesis Mangan Oksida}

Reaksi antara $\mathrm{KMnO}_{4}$ (kalium permanganat) dengan maltosa merupakan suatu bentuk reaksi oksidasi-reduksi (reaksi redoks). Mangan oksida dapat disintesis dari maltosa dan $\mathrm{KMnO}_{4}$. Larutan $\mathrm{KMnO}_{4}$ yang berwarna ungu tua setelah ditambahkan maltosa dan diaduk selama \pm 2 menit terjadi peningkatan suhu yang sangat cepat pada wadah reaksi. Warna campuran tersebut berubah menjadi coklat kehitaman yang membentuk sol $( \pm$ 2-10 menit). Sol ini akan mengalami polimerisasi membentuk gel. Gel dicuci dengan akuades untuk menghilangkan ion $\mathrm{K}^{+}$, menurut Ching dkk., pencucian sangat mempengaruhi struktur dari mangan oksida yang dihasilkan. Ion $\mathrm{K}^{+}$yang tinggi akan menghasilkan jenis mangan oksida dengan struktur berlapis, hal ini disebabkan karena struktur berlapis membutuhkan ion $\mathrm{K}^{+}$yag lebih banyak daripada struktur berongga dan flokulan gel yang telah dicuci dikeringkan pada suhu $110^{\circ} \mathrm{C}$ selama semalam untuk menghilangkan molekul air sehingga diperoleh xerogel. Kemudian xerogel yang dihasilkan dikalsinasi pada temperatur $450^{\circ} \mathrm{C}$ selama dua jam dan menghasilkan material yang berbentuk padatan berwarna hitam. Material tersebut dicuci kembali dengan $\mathrm{HCl}$ 0,1 $\mathrm{M}$ dan akuades, untuk kemudian dikeringkan pada temperatur $110^{\circ} \mathrm{C}$ sebelum dikarakterisasi. Adapun jumlah mangan oksida yang didapat pada sintesis menggunakan metoda sol-gel ini sebanyak $10,876 \mathrm{~g}$.

\section{Karakterisasi Mangan Oksida Difraksi Sinar-X (XRD)}

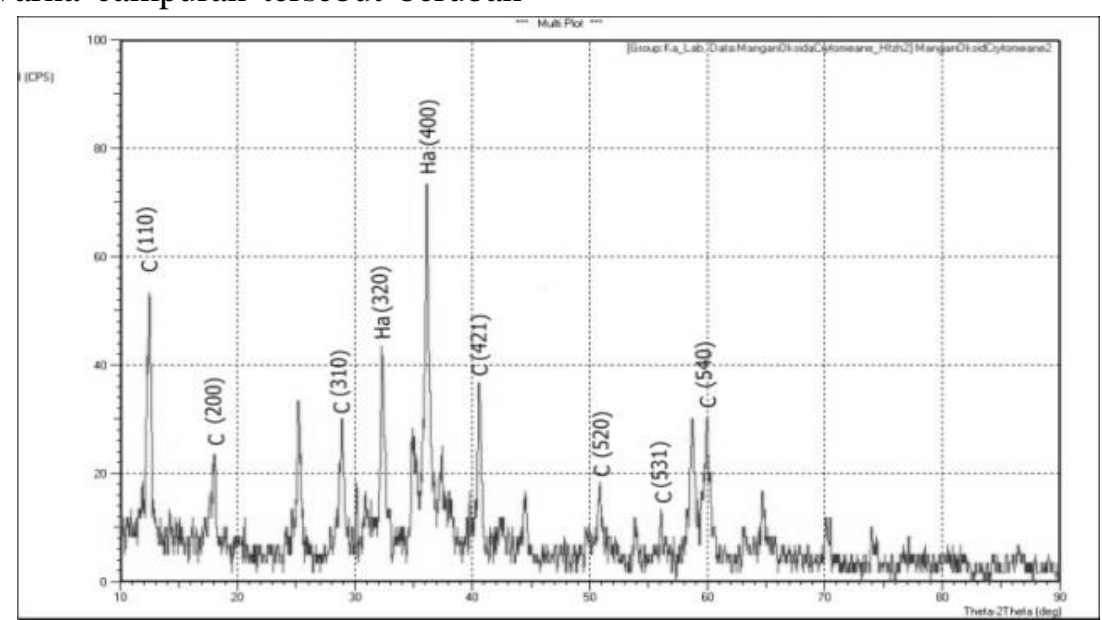

Gambar 1. Pola XRD mangan oksida dengan perbandingan mol $\mathrm{KMnO}_{4}$ : maltosa (4: 1).

Gambar 1 merupakan hasil difraktogram mangan oksida hasil sintesis dengan metode solgel menggunakan prekursor $\mathrm{KMnO}_{4}$ dan maltosa, Pola-pola difraksi dari gambar tersebut memperlihatkan bahwa terbentuk dua jenis fasa mangan oksida yaitu cryptomelane dan hausmanite dengan komposisi cryptomelane lebih dominan, namun hausmanite memiliki intensitas paling tinggi dapat dilihat dari bidang refleksi cryptomelane dengan puncak karakterisasi $2 \theta$ $12.5^{0}(110), 18.07^{0}$ (200), $28.9^{0}(300), 41.9^{0}$ (421), $50.7^{\circ}(520)$ dan $56.1^{0}(531)$, dan bidang refleksi hausmanite dengan puncak karakterisasi $2 \theta 32.3^{\circ}$ (320) dan $36.1^{0}$ (400). Penelitian sebelumnya menggunakan prekursor $\mathrm{KMnO}_{4}$ dan maltosa 
menghasilkan cryptomelane murni dengan metode sol-gel (Ginting, 2011)

\section{Scanning Electron Microscopy (SEM)}

Scanning Electron Microscopy (SEM) dilakukan untuk mengetahui morfologi dari mangan oksida hasil sintesis. Dari hasil SEM pada Gambar 2, partikel mangan oksida yang didapat berbentuk seperti gumpalan-gumpalan awan dan terdapat rongga-ronggaa dengan ukuran partikel \pm $1 \mu \mathrm{m}$. Kirillov dkk., (2009) mensintesis hausmanite dengan prekursor $\mathrm{Mn}_{3} \mathrm{O}_{4}$ dan $\mathrm{MnOOH}$ yang berbentuk seperti bulatan-bulatan kapas dan terdapat rongga pada saat dianalisis dengan SEM.

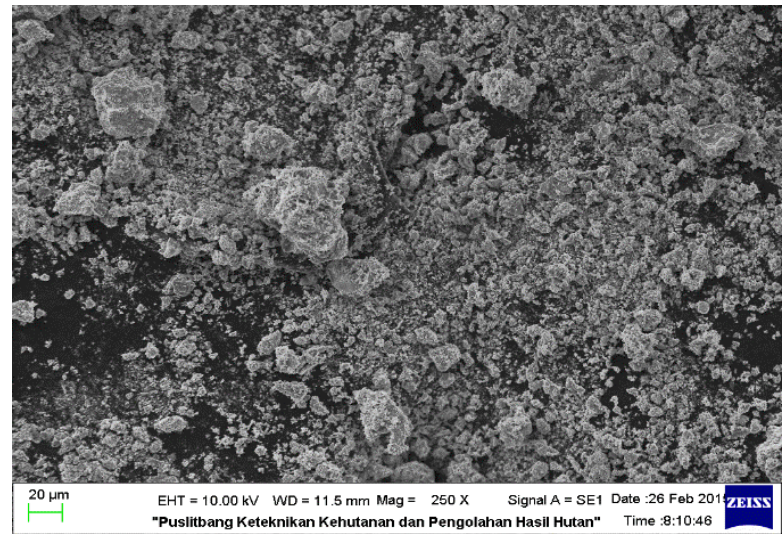

Gambar 2. SEM (Scanning Electron Microscopy) mangan oksida perbesaran 250x.

\section{Luas Permukaan Mangan Oksida}

Luas permukaan mangan oksida ditentukan dengan adsorpsi metilen biru dengan menggunakan Spectrophotometer. Serapan maksimum dari metilen biru diperoleh pada panjang gelombang $664 \mathrm{~nm}$. Luas permukaan dari mangan oksida yang didapat $10,716 \mathrm{~m}^{2} / \mathrm{g}$. Hasil pengukuran luas permukaan pada penelitian ini kurang sesuai dengan penelitian yang dilakukan oleh Ginting (2011). Ginting mengukur luas permukaan mangan oksida dengan metode adsorpsi sampel terhadap metilen biru dengan luas permukaan $3,155 \mathrm{~m}^{2} / \mathrm{g}$.

\section{Proses Oksidasi Fenol}

Hasil oksidasi larutan fenol 100 ppm yang diberi penambahan $0,1 \mathrm{~g}$ katalis mangan oksida dan $10 \mathrm{~mL} \mathrm{H}_{2} \mathrm{O}_{2} 30 \%$ dapat dilihat pada Gambar 3.

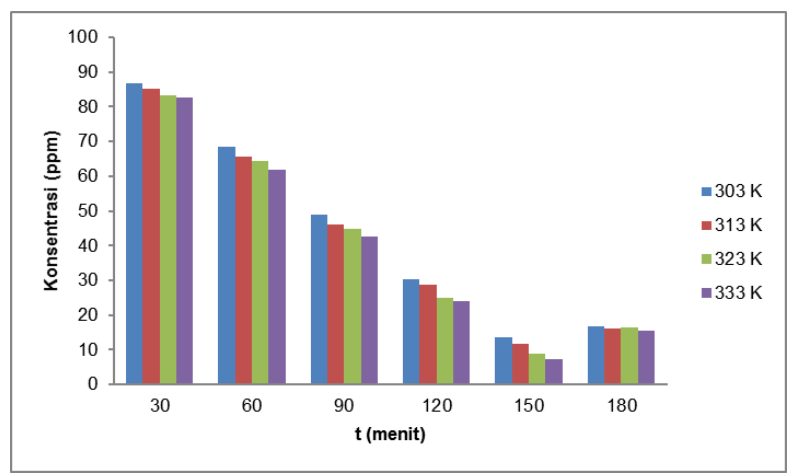

Gambar 3. Pengaruh suhu reaksi oksidasi fenol (konsentrasi awal fenol 100 ppm, katalis $0.1 \mathrm{~g}$ ).

Hasil pengukuran kadar fenol sisa dalam proses oksidasi fenol menggunakan katalis mangan oksida pada Gambar 3 menunjukkan waktu optimal pada saat $t=150$ menit dengan penurunan persentase degradasi fenol sebesar 92,7\% dimana konsentrasi fenol sisa 7,36 ppm. Pada saat $\mathrm{t}=180$ menit, terjadi peningkatan konsentrasi fenol dibandingkan $\mathrm{t}=150$. Hal ini mungkin diakibatkan terjadinya desorpsi fenol yang sebelumnya telah teradsorpsi pada proses degradasi.

Lestari (2012) telah melakukan penelitian degradasi fenol menggunakan nanokatalis $\mathrm{CuO} / \mathrm{TiO}_{2}$. Hasil pengukuran menunjukkan waktu optimum pada $\mathrm{t}=50$ menit yaitu sebesar $60,63 \%$, selanjutnya mengalami penurunan persentase degradasi pada $\mathrm{t}=110$ menit. Ketidaksesuaian ini diakibatkan oleh fenol yang telah jenuh oleh mangan oksida, maka pemisahan fenol dengan mangan oksida menjadi lebih sukar. Larutan yang jenuh mempengaruhi proses pembacaan absorbansi pada sampel.

Kebergantungan laju oksidasi penurunan kadar fenol terhadap konsentrasi dalam reaksi juga dapat ditentukan melalui orde reaksinya dengan menggunakan metode grafik yang dicoba pada 3 tingkatan orde, yaitu orde ke- 0 , ke-1, ke-2. Penentuan orde reaksi dilakukan dengan membandingkan nilai $R^{2}$ nya. Nilai $R^{2}$ yang tertinggi merupakan orde yang sesuai dengan data konsentrasinya (Atkins, 1999)

Berdasarkan hasil penelitian, laju oksidasi fenol dengan menggunakan katalis mangan oksida mengikuti orde 1 . 
Tabel 1. Data konsentrasi pada orde 0,1 dan 2 (konsentrasi fenol $100 \mathrm{ppm}$, katalis mangan oksida $0,1 \mathrm{~g}$, suhu $30^{\circ} \mathrm{C}$ )

\begin{tabular}{cccc}
\hline $\begin{array}{c}\text { Waktu } \\
(\mathrm{t})\end{array}$ & $\begin{array}{c}\mathrm{C}(\mathrm{ppm}) \\
(\text { Ord 0) }\end{array}$ & $\begin{array}{c}\ln \mathrm{C} \\
(\text { Orde 1) }\end{array}$ & $\begin{array}{c}1 / \mathrm{C} \\
(\text { Orde } 2)\end{array}$ \\
\hline 30 & 86.67662 & 4.462184 & 0.011537 \\
60 & 68.56716 & 4.227814 & 0.014584 \\
90 & 49.0597 & 3.893038 & 0.020383 \\
120 & 30.30348 & 3.411263 & 0.033 \\
150 & 13.73632 & 2.620043 & 0.0728 \\
180 & 16.67164 & 2.813709 & 0.059982 \\
\hline
\end{tabular}

Berdasarkan uji terhadap orde ke 0, 1 dan 2, maka diperoleh nilai koefisien determinan $\left(\mathrm{R}^{2}\right)$ sebesar 0,9513 pada orde ke 1 . Nilai koefisien determinan dari masing-masing tingkatan orde sebagai berikut:

Tabel 2. Perbandingan Tingkatan Orde dengan nilai $\mathrm{R}^{2}$

\begin{tabular}{ll}
\hline Orde & $\mathrm{R}^{2}$ \\
\hline 0 & 0.942 \\
1 & 0.9513 \\
2 & 0.8634 \\
\hline
\end{tabular}

Berdasarkan Tabel 2 diketahui bahwa orde ke1 memiliki nilai koefisien determinan lebih besar daripada orde ke-0 dan orde ke-2.

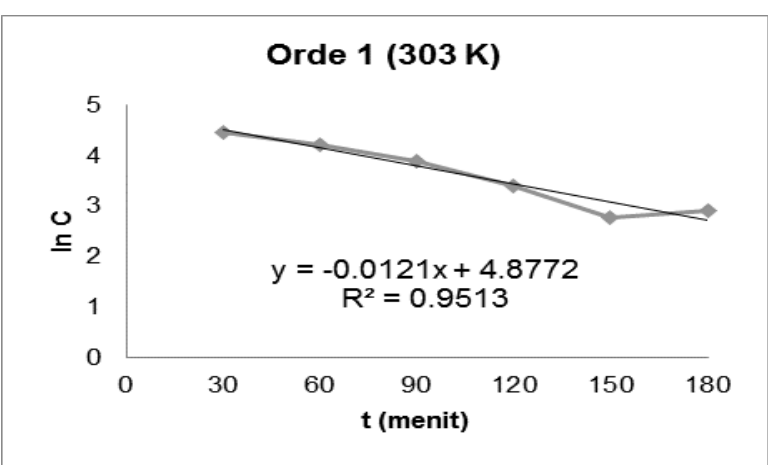

Gambar 6. Grafik Uji kelinieran data konsentrasi dengan orde ke 1 (konsentrasi fenol 100 ppm, katalis mangan oksida $0.1 \mathrm{~g}$, suhu $\left.30^{\circ} \mathrm{C}\right)$

Hubungan antara suhu dengan besarnya konstanta kecepatan reaksi dapat menggunakan persamaan (2.22)
Tabel 3. Parameter Arrhenius Penurunan Konsentrasi Fenol

\begin{tabular}{cccc}
\hline $\mathrm{T}$ & $1 / \mathrm{T}$ & $\mathrm{k}$ & $\ln \mathrm{k}$ \\
\hline 303 & 0.0033 & 0.0121 & -4.41455 \\
313 & 0.003195 & 0.0124 & -4.39006 \\
323 & 0.003096 & 0.0127 & -4.36615 \\
333 & 0.003003 & 0.0131 & -4.33514 \\
\hline
\end{tabular}

Penentuan persamaan Arrhenius dilakukan dengan membuat plot nilai $\ln \mathrm{k}$ dan $1 / \mathrm{T}$ pada reaksi penurunan konsentrasi fenol.

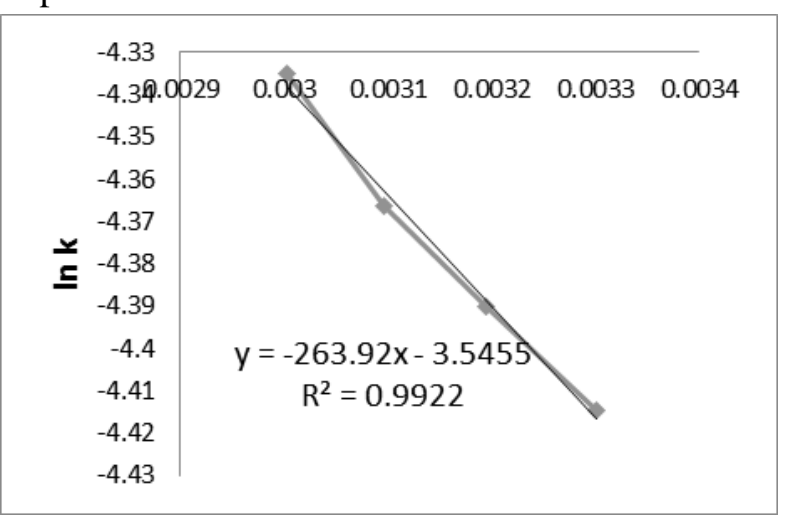

Gambar 7. Grafik analisis linier dari plot $1 / \mathrm{T}$ dan $\ln \mathrm{k}$.

Berdasarkan Gambar 7 didapat persamaan: y $=-263.92 \mathrm{x}-3.5455$. Adapun nilai energi aktivasi sebesar 2,19 kJ/mol. Muhammad dkk., (2012) telah mempelajari kajian kinetika pada reaksi oksidasi fenol menggunakan katalis Co/ANZ, energi aktivasi yang didapat sebesar 48, $\mathrm{kJ} / \mathrm{mol}$. Saputra dkk., (2013) juga mempelajari kajian kinetika pada reaksi degradasi fenol menggunakan persamaan Arrhenius, energi aktivasi yang diperoleh sebesar 11,4 kJ/mol.

\section{KESIMPULAN DAN SARAN}

\section{Kesimpulan}

Dari hasil penelitian yang dilakukan, diperoleh kesimpulan sebagai berikut:

1. Hasil sintesis mangan oksida yang diperoleh dianalisis dengan difraksi sinar-x, tipe mangan oksida yang dihasilkan berupa mangan oksida hausmanite dan cryptomelane. Luas permukaan mangan oksida yang dihasilkan dengan menggunakan metode adsorpsi metilen biru sebesar $10,716 \mathrm{~m}^{2} / \mathrm{g}$. 
2. Efisiensi oksidasi fenol meningkat seiring dengan meningkatnya suhu reaksi. Fenol teroksidasi sebesar $86 \%$ pada suhu reaksi $30^{\circ} \mathrm{C}$, menit ke 120 , sedangkan pada suhu reaksi $60^{\circ} \mathrm{C}$ fenol teroksidasi sebesar $92,7 \%$.

3. Studi kinetika menunjukkan bahwa oksidasi fenol mengikuti orde ke-1 dengan energi aktivasi sebesar $2,19 \mathrm{~kJ} / \mathrm{mol}$.

\section{Saran}

Sebaiknya dilakukan adanya penelitian lanjutan untuk penentuan luas permukaan yaitu dengan menggunakan metode BET. Pada proses oksidasi fenol sebaiknya dilakukan variasi konsentrasi $\mathrm{H}_{2} \mathrm{O}_{2}$ yang digunakan.

\section{DAFTAR PUSTAKA}

Atkins PW. 1999. Kimia Fisika. "Ed ke-2 Kartahadiprodjo Irma I, penerjemah ; Indarto Purnomo Wahyu, editor. Jakarta: Erlangga. Terjemahan dari: Physichal Chemistry.

Chaliha, S., dan Bhattachryya, K.G.B. 2006. Catalytic Wet Oxidation of Phenol and Its Derivatives with $\mathrm{Fe}_{2} \mathrm{O}_{3}$ and $\mathrm{MnO}_{2}$. Gauhati University. India. J. Chem. Technology. Vol. 13. pp. 499-504.

Dewilda, Y., Arfianita, R., Iman, F.F. 2012. Degradasi Senyawa Fenol oleh Mikroorganisme Laut. J. Teknik Lingkungan. Vol 9. No 1. pp. 59-73.

Ginting, N. 2011. Pembuatan Mangan Oksida Cryptomelane dari Maltosa dan $\mathrm{KMnO}_{4}$ dengan Metode Sol-Gel. Fakultas Matematika dan Ilmu Pengetahuan Alam Universitas Riau, Pekanbaru

Inchaurrondo, N. S., Massa, P., Fenoglio, R., Font, J. and Haure, P. 2012. Efficient catalytic wet peroxide oxidation of phenol at moderate temperature using a high load-supported copper catalyst. Chemical Engineering Journal. 426-434.

Kirillov, S.A., Aleksandrova, V.S., Lisnycha, T.V., Dzanashvili, D.I., Khainakov, S.A., Garcia, J.R. 2009. Oxidation of Synthetic Hausmanite $\left(\mathrm{Mn}_{3} \mathrm{O}_{4}\right)$ to Manganite. J.of Melecular Structure. pp. 89-94.

Lestari, M. W. 2012. Sintesis dan Karakterisasi Nanokatalis $\quad \mathrm{CuO} / \mathrm{TiO}_{2} \quad$ yang
Diaplikasikan Pada Proses Degradasi Limbah Fenol. Fakultas Matematika dan Ilmu Pengetahuan Alam Universitas Negeri Semarang.

Liu, Z., Ooi, K. 2003. Preparation and AlkaliMetal Ion Extraction/ Insertion Reactions with Nanofibrous Manganese Oxide Having 2 _ 4 Tunnel Structure. J. Chem Mater. 16: 4296-4303

Matsuda, E. Tanaka, S. Koike, K. Tanaka, A. Sano, M. Miyake, T. 2007. Synthesis of One-Dimensional Microporous Todorokite and its Catalytic Activity in CO Oxidation. J. of. Chem. Intermediet. Vol. 34. No. 5-7. pp. 535-549.

Muhammad, S., Shukla, P.R., Wang, S., Tade, M.O. 2011. Heterogeneous Catalytic Oxidation of Phenol for Wastewater Treatment Using Ruthenium Catalyst. $J$. of. Chemical Engineering.

Munter, R. 2001. Advanced Oxidation Processes Curent status and prospects. Proc. Estonian Acad. Sci. Chem. 50(2): 59-80.

Saputra, E. Muhammad, S. Sun, H. Ang, H.M. Tade, M.O. Wang, S. 2013. Manganese Oxides at Different Oxidation States For Heterogeneous Activation Of Peroxymonosulfate For Phenol Degradation in Aqueous Solutions. J. of. Catalysis B: Environmental. pp. 729735.

Slamet, Arbianti, R. dan Daryanto. 2005. Pengolahan Limbah Organik (Fenol) dan Logam Berat $\left(\mathrm{Cr}^{6+}\right.$ atau $\left.\mathrm{Pt}^{4+}\right)$ Secara Simultan dengan Fotokatalis $\mathrm{TiO}_{2}, \mathrm{ZnO}-$ $\mathrm{TiO}_{2}$, dan CdS-TiO 2 . Makara, Teknologi. Vol 9. No. 02. pp. 66-71.

Valkaj, K.M., Wittine, O., Margeta, K., Granato, T., Katovic, A., Zrncevic, S. 2011. Phenol Oxidation with Hydrogen Peroxide using $\mathrm{Cu} / \mathrm{ZSM} 5$ and $\mathrm{Cu} / \mathrm{Y} 5$. J.of. Chemical Techology. Vol. 13. No. 3. pp. 28-36.

Wang, P., Bian, X. F., and Li, Y. X. 2012. Catalytic oxidation of phenol in wastewater - A new application of the amorphous $\mathrm{Fe}_{78} \mathrm{Si}_{9} \mathrm{~B}_{13}$ alloy. Chinese Science Bulletin. 57(1): 33-40. 
Zhou, S., Qian, Z., Sun, T., Xu, J., Xia, C. 2011. Catalytic Wet Peroxide Oxidation of Phenol Over Cu-Ni-Al Hydrotalcite. $J$. of. Applied Clay Science. No. 53. pp. 627-633
Zultinar., Yenti, S.R. 2011. Adsorbsi Fenol dengan Adsorben Kitin. J. Pilar Sains. Vol. 11. No. 1. pp. 38-42 